\title{
Effect of Micronization on the Extent of Drug Absorption from Suspensions in Humans
}

\author{
Doo-Man Oh', Rane L. Curl', Chul-Soon Yong ${ }^{3}$ and Gordon L. Amidon ${ }^{4}$ \\ 'College of Pharmacy, Catholic University of Taegu-Hyosung, Kyungsan, Kyungbuk 713-702, Korea, ${ }^{2}$ Department \\ of Chemical Engineering, The University of Michigan, Ann Arbor, MI 48109, U.S.A., ${ }^{3}$ College of Pharmacy, Yeung- \\ nam University, Gyongsan 712-749, Korea and ${ }^{4}$ College of Pharmacy, The University of Michigan, Ann Arbor, MI \\ 48109-1065, U.S.A.
}

(Received August 11, 1995)

\begin{abstract}
A microscopic mass balance approach has shown that the initial saturation $(/ s)$, absorption number $(A n)$, dose number $(D o)$, and dissolution number $(D n)$ are four fundamental dimensionless parameters that can be used to estimate the fraction dose absorbed $(A)$ of suspensions of poorly soluble drugs in humans. The dissolution number of a drug increases with decreasing its particle size. The effect of micronization on $F$ for suspensions was investigated in terms of $D n$. About $90 \%$ of maximal $F$ can be achieved at $D n \approx 2$. Increasing the solubility of a drug results in better oral absorption through increasing $D n$ and decreasing $D o$. The fractions dose absorbed of digoxin, griseofulvin, and benoxaprofen agree with predicted $F$ values using estimated parameters. Drugs with low $D o$ and low $D n$ can be more completely absorbed by reducing particle size, while absorption of drugs with high Do and low Dn is limited by solubility and requires higher solubility to enhance the fraction dose absorbed in addition to micronization. Solubility at the physiological pH should be used for the estimation of the fraction dose absorbed.
\end{abstract}

Key Words : Absorption, Dose Particle size, Permeability, Solubility

\section{INTRODUCTION}

It has been shown that the absorption of several poorly soluble drugs administered in suspension formulations is dissolution-rate limited (Abdou, 1989). According to the dissolution equation derived from the film theory, dissolution rate is directly proportional to the surface area, the solubility of a compound, and its concentration gradient across the diffusion layer. In general, micronization of a compound enhances the dissolution rate due to the increase in surface area available to the dissolving medium. The dissolution rate can also be increased by increasing the solubility, which is usually accomplished by $\mathrm{pH}$ effect, salt formulation, solubilization by surface active agents, change in crystal form, complexation, or by a sufficient reduction in particle size (Leeson and Carstensen, 1974). Increasing the dissolution rate usually results in more rapid and complete absorption. Poor aqueous solubility may cause a slow dissolution rate. Recently the im-

Correspondence to: Doo-Man Oh, College of Pharmacy, Catholic University of Taegu-Hyosung, Kyungsan, Kyungbuk 713-702, Korea portance of the dose to solubility ratio on the extent of absorption has been discussed (Dressman, 1989; Sinko et al., 1991).

There are instances in which particle size reduction fails to increase the absorption rate of a drug (Gibaldi, 1984). For drugs with aqueous solubilities below 0.1 $\mathrm{mg} / \mathrm{ml}$, micronization may not be enough to get complete oral absorption depending on the dose. Micronization sometimes dramatically increases the tendency of a drug powder to aggregate, which may lead to a decrease in effective surface area. The effective surface area of hydrophobic drug particles may be increased by the addition of a wetting agent to the formulation.

A microscopic mass balance approach has been employed for prediction the bioavailability of suspensions (Oh et al., 1993) and the drug-drug interaction (Oh and Amidon, 1995). It was shown by Oh et al. (1993) that the fraction dose absorbed $(F)$ from suspensions of poorly soluble compounds is governed by four fundamental dimensionless parameters: initial saturation $(/ s)$, absorption number $(A n)$, dose number $(D o)$, and dissolution number $(D n)$. The effects of particle size and solubility on $F$ from suspensions can be explained by $D n$ and Do. The ob- 
jectives of this report are to demonstrate the effects of micronization and solubilization on the fraction dose absorbed from suspensions of poorly soluble drugs and to determine when micronization can significantly increase $F$. Furthermore the $\mathrm{pH}$ effect on solubility for weak electrolytes will be discussed in order to estimate $F$.

\section{Fraction dose absorbed of suspensions}

To predict the fraction dose absorbed from suspensions of poorly soluble compounds, a microscopic mass balance approach has been developed (Oh et al., 1993). A physical tube model with a plug flow containing particles is employed. The length of the intestine is $L$ with radius $R$ and initial radius of particles is $r_{0}$. Mass balances in both solid phase and solution phase were considered to get the set of differential equations:

$$
\begin{aligned}
& \frac{d r^{*}}{d z^{*}}=-\frac{D n}{3} \cdot \frac{1-C^{*}}{r^{*}} \\
& \frac{d C^{*}}{d z^{*}}=D n \cdot D o \cdot r^{*}\left(1-C^{*}\right)-2 A n \cdot C^{*}
\end{aligned}
$$

where,

$$
\begin{aligned}
& \text { An }=\frac{P_{\text {eff }}}{Q /(\pi R L)} \\
& \text { Do }=\frac{M_{0} N_{0}}{C_{s}} \\
& \text { Dn }=\frac{\left(D / r_{0}\right) C_{s}\left(4 \pi r^{2}\right) /\left(\frac{4}{3} \pi r_{0}^{3} \rho\right)}{Q /\left(\pi R^{2} L\right)}
\end{aligned}
$$

$P_{\text {eff }}$ is the effective wall permeabilty, $Q$ is the volumetric flow rate in the intestine, and $M_{0}$ is the dose taken with water volume of $V_{0}$ for dimensionless parameters, $z^{*}=\mathrm{z} / \mathrm{L}, \mathrm{r}^{*}=\mathrm{r}_{\mathrm{p}} / \mathrm{r}_{0}$, and $C^{*}=C_{L} / C_{\mathrm{s}}$ where $\boldsymbol{Z}$ is the axial coordinate down the intestine and $r_{p}$ and $C_{L}$ are the radius of particles and the luminal concentration at $z$, respectively. $C_{s r} D$, and $\rho$ are the solubility, diffusivity, and density of the compound, respectively. $A n$ is the absorption number, which is the ratio of radial absorption rate to axial convection rate, $D o$ is the dose number, which is the ratio of dose concentration to solubility of a compound, and $D n$ is the dissolution number, which is the ratio of residence time in the intestine to dissolution time from initial particles.

To estimate the extent of drug absorption, it is assumed that the dose taken is the sum of the initially dissolved amount is solution and the remaining amount in solid at the beginning of the intestine. The initial saturation, $s$, is defined to be:

$$
\text { Is }=C_{L}(0) / C_{s}
$$

where $C_{L}(0)$ is the luminal concentration at the beginning of the intestine. $I s$ is the dimensionless inlet concentration in solution. For poorly soluble drugs, is is close to zero so that $C^{*}=0$ and $r^{*}=1$ at the beginning of the intestine $\left(z^{*}=0\right)$.

It is assumed that the difference between mass in and mass out of the intestine is equal to be the mass absorbed at steady state. From the mass balance in the intestine, the fraction dose absorbed $(F)$ is:

$$
F=1-\left\{r^{*}(1)\right\}^{3}-\frac{C^{*}(1)}{D o}
$$

where $r^{*}(1)$ and $C^{*}(1)$ are the dimensionless radius of particles and the dimensionless concentration at the end of the intestine. The values of $r^{*}(1)$ and $C^{*}(1)$ can be calculated from Eqs. (1) and (2) by a numerical method (Oh et al., 1993).

\section{Simulation}

Differential equations were solved by the RungeKutta-Merson method. Simulation was performed with a personal computer using a NDP Fortran-386 compiler (Microway, Inc., Kingston, MA). The absorption number $(A n)$ of griseofulvin is about 7 and was calculated from single-pass perfusion data in rats (Poelma, 1989). The value of $A n$ for other drugs in assumed to be 7 , based on the fact that they are nonpolar of moderate moleular weight (Sinko et al., 1991). The conclusion would be essentially the same for any $A n$ greater than about 1 (Oh et al., 1993). The initial saturation was assumed to be $0\left(r^{*}=1\right.$ and $\mathrm{C}^{*}=0$ at $\mathrm{z}^{*}=0$ ) because most poorly soluble drugs have very slow dissolution rates. The volume flow rate was assumed to be $1 \mathrm{ml} / \mathrm{min}$, and the luminal volume was taken to be $250 \mathrm{ml}$ if it was not given in the literature. Dose number and dissolution number were calculated by Eqs. (4) and (5), respectively.

\section{RESULTS AND DISCUSSION}

It has been shown in the previous paper (Oh et al., 1993) that there are four fundamental dimensionless parameters to estimate the fraction dose absorbed $(A)$ of suspensions: initial saturation $(/ s)$, absorption number $(A n)$, dose number $(D o)$, and dissolution number $(D n)$. Fig. 1 shows a three dimensional graph and contour for the fraction dose absorbed in the plot of dose number versus dissolution number at $A n=5$ and $l s=0$. It is clearly demonstrated that $F$ is dependent on both $D o$ and $D n$ at a fixed $A n$. In addition to $D o$ and $D n, A n$ can vary $F$ (Oh et al., 1993). In general, the fraction dose absorbed may be limited by low $A n$, low $D n$, or high $D o$, or by any combination thereof. For example, a drug with high $A n$, low $D o$ and high $D n$ is well absorbed. As shown in Fig. 2, an increase 


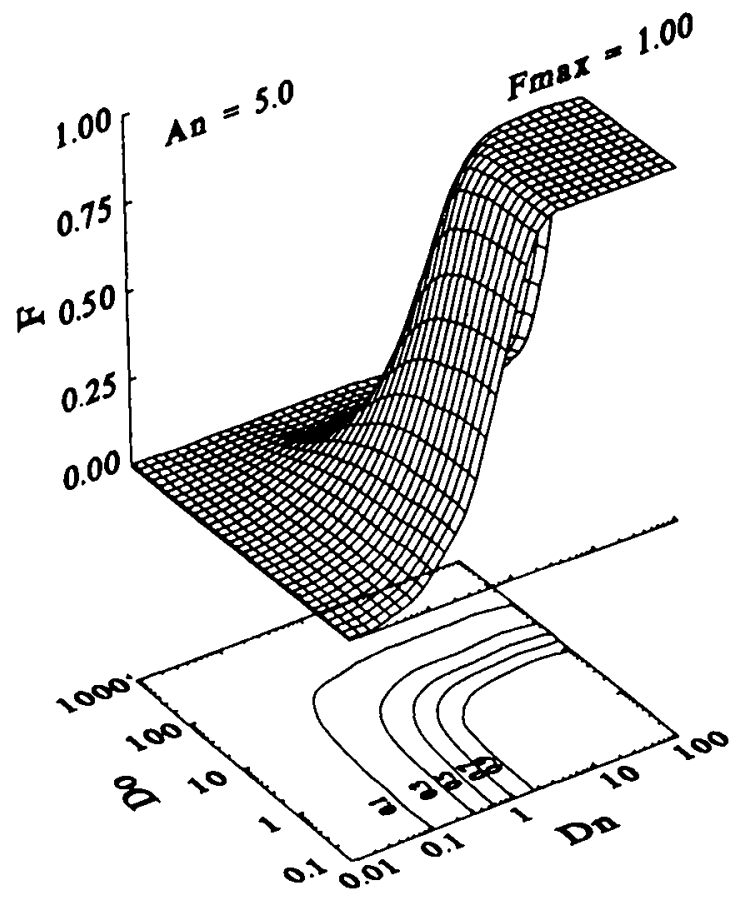

Fig. 1. Three dimensional graph and contour of the fraction dose absorbed $(F)$ in the polt of dose number $(D o)$ versus dissolution number $(D n)$ at $A n=5$ and $l s=0$.

$$
D_{0}=100
$$

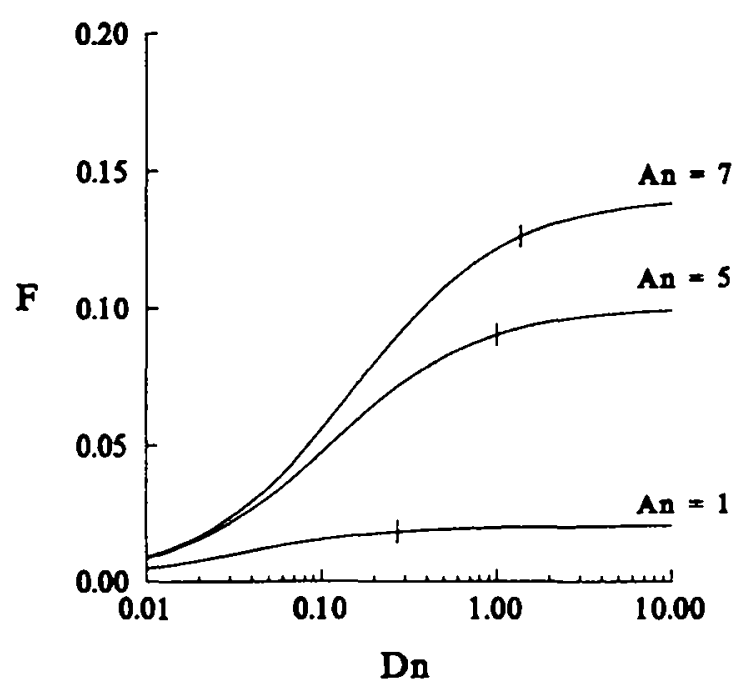

Fig. 2. Plot of fraction dose absorbed $(F)$ versus dissolution number $(D n)$ at several different absorption numbers $(A n=1$, $5,7)$. Bar $(I)$ indicates $90 \%$ of maximal $F$ which can be obtained at no dissolution limitation. Values of parameters used for calculations: $D o=100, l s=0$.

in $A n$ results in higher $F$. However, absorption cannot be complete only by increasing $A n$ and $D n$ if $D o$ is too high. Fig. 2 shows that $F$ is about 0.15 at $D o=100$ even when $A n$ is 7 . Fig. 3 shows a plot of the fraction dose absorbed versus dissolution number at several dose numbers. At higher $D n$, the reduction in $F$ is significant with increasing $D o$. If a drug has a low $A n$ and/or high $D o$, its chemical structure needs to be

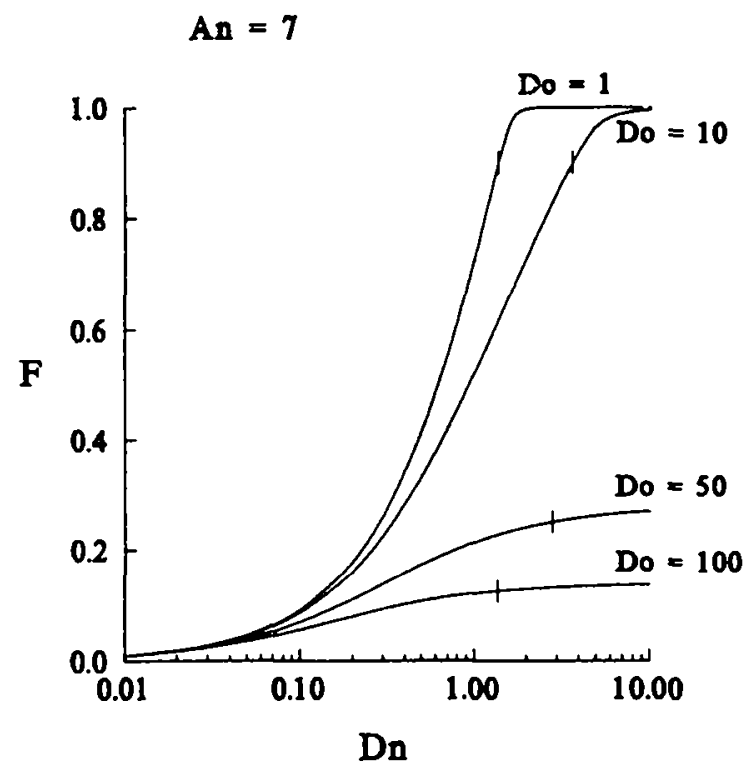

Fig. 3. Plot of fraction dose absorbed $(F)$ versus dissolution number $(D n)$ at several different dose numbers $(D o=1,10$, $50,100)$. Bar $(I)$ indicates $90 \%$ of maximal $F$ which can be obtained at no dissolution limitation. Values of parameters used for calculations: $A n=7, / s=0$.

modified to obtain a better wall permeability, higher solubility and higher potency. Taking more water is also favorable to $F$ through decreasing $D o$.

Another way to increase the fraction dose absorbed of a drug is to increase $D n$. The dissolution number is the ratio of residence time in the intestine to the dissolution time of the particles, and is a function of solubility, diffusivity, density, initial particle radius of a drug, and volumetric flow rate in the intestine. A typical way to increase $D n$ in pharmaceutics is to reduce the particle size, since $D n$ is inversely proportional to the square of the initial radius of the particles. However $F$ reaches a plateau as $D n$ increases (Fig. 2).

Ten percent $\left(0.1 \cdot F_{\max }\right)$ and $90 \%\left(0.9 \cdot F_{\text {max }}\right)$ of maximal $F$ (obtained at no dissolution limitation; $D n \rightarrow \infty$ ) are shown in Fig. 4, illustrating that $0.9 \cdot F_{\max }$ can be achieved in the range of 1 to 3 of Dn. Bars in Fig. 2 and Fig. 3 also indicate $90 \%$ of maximal $F$. This points out that the micronization does not increase $F$ significantly if $D n$ is larger than about 2 . In this case $F$ is limited by other variables such as $D o$ and we refer to this as solubility (or dose number) limited absorption. A compound that falls in the region between $0.1 \cdot F_{\max }$ and $0.9 \cdot F_{\max }$ is most sensitive to micronization.

Digoxin and griseofulvin were chosen because they have similar solubilities but quite different doses. Solubilities of digoxin and griseofulvin are $0.024 \mathrm{mg} / \mathrm{ml}$ and $0.015 \mathrm{mg} / \mathrm{ml}$, respectively. The dose number of digoxin ranges from 0.1 to 0.5 (dose of 0.25 to 0.5 $\mathrm{mg}$ ), while that of griseofulvin ranges 67 to 267 (dose 

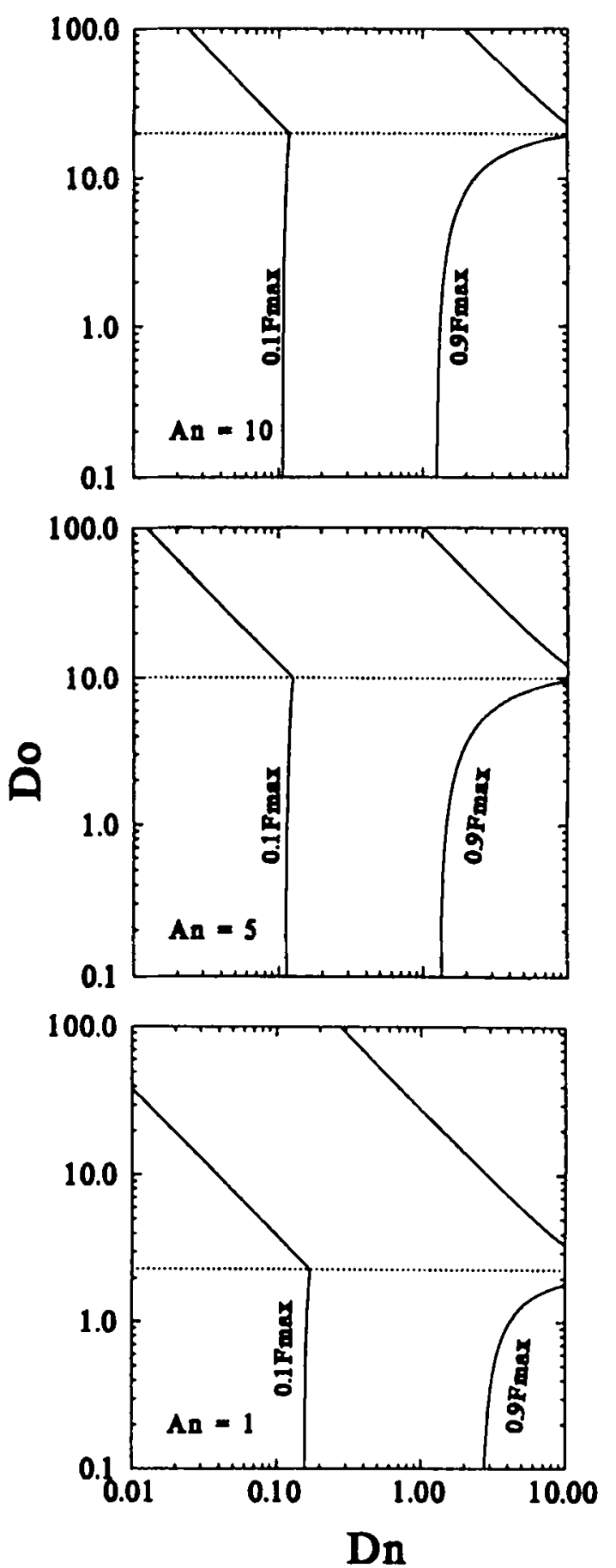

Fig. 4. Ten percent $\left(0.1 \cdot F_{\max }\right)$ and $90 \%\left(0.9 \cdot F_{\max }\right)$ of maximal $F$ (at no dissolution limitation; $D n \rightarrow \infty$ ) in the plot of $D o$ versus $D n$ for $A n$ of 1,5 , and 10 . Dotted lines represent the dose numbers at $\mathrm{Dn} \rightarrow \infty$.

of 250 to $1000 \mathrm{mg}$ ). Fig. 5 shows the fraction dose absorbed of digoxin at various $D n$. Predicted values are calculated using $D o=0.1, A n=7$, and $l s=0$, and reported data were taken from the literature (Jounela et al., 1975; Johnson et al., 1978). Good agreement between reported and predicted fractions dose absorbed is observed. A Dn of 1.3 (particle radius of 26 $\mu \mathrm{m})$ results in $90 \%$ absorption. Jounela et al. (1975) reported that the bioavailability of digoxin with mean

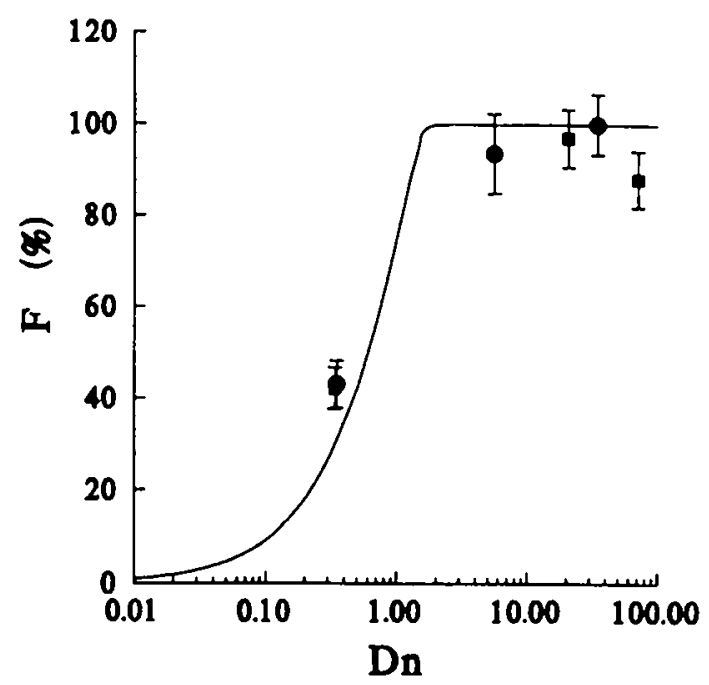

Fig. 5. Fraction dose absorbed $(F)$ of digoxin. Predicted values are shown by a solid line. Values of parameters used for calculations: $D o=0.1, A n=7, i s=0$. Human dat were taken from Jounela et al. (1975) and Johnson et al. (1978).

- : Johnson et al. (1978), a : Jounela et al. (1978)

particle radii of 3.5 or $6.5 \mu \mathrm{m}$ was 78 to $97 \%$, while that with larger particle size $(51 \mu \mathrm{m})$ was only $39 \%$. It was also demonstrated that absorption from a formulation of particle radius of 45 to $53 \mu \mathrm{m}$ was reduced about $43 \%$ of that of micronized digoxin ( $5 \mu \mathrm{m}$ of radius) (Johnson et al., 1978). The present analysis suggests that complete oral absorption of digoxin may be expected if particle radius is smaller than $26 \mu \mathrm{m}$. There are however some conflicting reports in the literature. Shaw and Carless (1974) found in human patients that the bioavailability of digoxin with a particle radius of $11 \mu \mathrm{m}$ was about $46 \%$ compared to that when given in solution, and that reduction of mean particle radius from $11 \mu \mathrm{m}$ to $1.85 \mu \mathrm{m}$ resulted in $31 \%$ increase in mean digoxin plasma level. There is a significant shift to the right on the plot of $F$ versus $D n$, indicating that more micronization is required to get the same $F$ in patients. The reason for this discrepancy is not known. It may be from shifts on Dn and $A n$. However the comparison of bioavailability data from patients with those of healthy volunteers cannot be possible without any attempt to normalize the human data.

In the case of griseofulvin, Do is very high so that the $D o$ limitation of $F$ may be expected even if $D n$ is large. Fig. 6 shows the fraction dose absorbed of griseofulvin with predicted lines for $D o=67$ and $D o=$ 267 . Reported $F$ values were scattered over the range estimated, partly due to its absorption variability (Atkinson et al., 1962; Khalafalla et al., 1980; Terhaag et al., 1985). Each point in Fig. 6 has various Do ranging 67 to 267, even if they are from the same report. Micronization may play a role to increase $F$, but particle size in most formulations of griseofulvin is already small enough so that $D n$ is much larger 
than 2. Therefore reducing the particle size does not increase $F$ very much, without reducing $D o$. This may be a reason that a meaningful correlation between dissolution rate and extent of griseofulvin absorption was not observed (Khalafalla et al., 1980). It was suggested from Fig. 6 that the variability in bioavailability might result primarily from high $D o$. To increase $F$ of griseofulvin, Do must be reduced by enhancing its solubility. It may, in part, expain the better absorption of griseofulvin in the fed state. Physiolgical surface active agents, like bile salts and lysolecithin, probably facilitate the dissolution and absorption of poorly water-soluble drugs in the small intestin (Miyazaki et al., 1980).

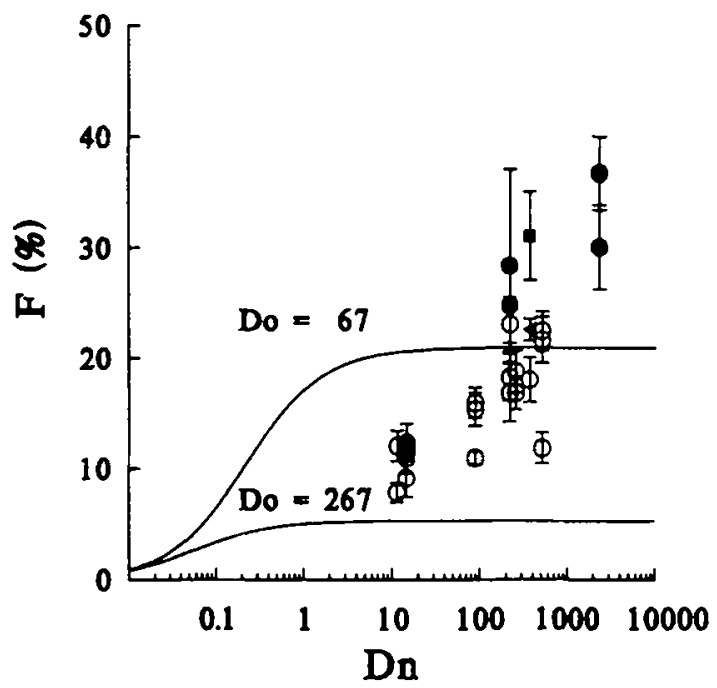

Fig. 6. Fraction dose absorbed $(F)$ of griseofulvin. Predicted values are shown by solid lines. Values of parametrers used for calcuations: $D o=67$ and $267, A n=7, i s=0$, Human data were taken from Atkinson et al. (1962), Khalafalla et al. (1980), and Terhaag et al. (1985).

0 : Atkinson et al. (1962)-tablets, : Atkinson et al. (1962)capsules, 4: Khalaflla et al. (1980), : Terhasg et al. (1985)
To improve bioavailability of suspensions in practical situations, the physicochemical properties of interest are the radius of particles and solubility, in addition to the dose taken. Contours of the fraction dose absorbed in the plot of solubility and the radius of particles for two different initial dose concentrations $(2 \mathrm{mg} / \mathrm{ml}$ or $0.1 \mathrm{mg} / \mathrm{ml})$ are shown in Fig. 7. It shows the dependency of $F$ on the dose concentration, the solubility, and the radius of the particles. For drugs with a high dose concentration and low solubility (as with griseofulvin), the effect of micronization may not be significant (Fig. $7(A)$ ). On the other hand, drugs with low dose concentration and low solubility (such as digoxin) may be completely absorbed by reducing their particle size (Fig. 7(B)).

Ridolfo et al. (1979) reported that solubilities of benoxaprofen, an antiinflammatory drug, were dramatically changed with increasing $\mathrm{pH}$. Higher solubility at higher $\mathrm{pH}$ decreases $D o$ and increases $D n$, resulting in a greater fraction dose absorbed. The simulations in Figs. 1 to 4 don't apply to benoxaprofen, since $/ s$ value is expected to vary as a function of $\mathrm{pH}$. Changing solubility makes is to increase at higher $\mathrm{pH}$ values. Fig. 8 shows the fraction dose absorbed of benoxaprofen at various $\mathrm{pH}$ values with two different $/ s$ values ( $/ s=0$ and 1$)$. It shows estimated data of $F$ at two different particle sizes $(9.25 \mu \mathrm{m}$ and $305 \mu \mathrm{m})$ of benoxaprofen and the reported values of $F$ in the literature (Wolen et al., 1979). As expected, estimated $F$ increases with increasing $\mathrm{pH}$, pointing out that the physiological $\mathrm{pH}$ should be used to estimate $F$ for weak electrolytes. In case of benoxaprofen the proper $\mathrm{pH}$ is 6 to 7 to estimate $F$ in humans (Fig. 8). Several estimated $F$ values of benoxaprofen at $\mathrm{pH} 7.0$ were shown in Table I, which is in good agreement with reported $F$ values (Ridolfo et al., 1979; Wolen et al., 1979; Nash et al., 1980). It should be pointed out that $l s=1$ rather than $l s=0$ may be appropriate at the
(A) $\mathrm{Mo} / \mathrm{Vo}=2 \mathrm{mg} / \mathrm{mL}$

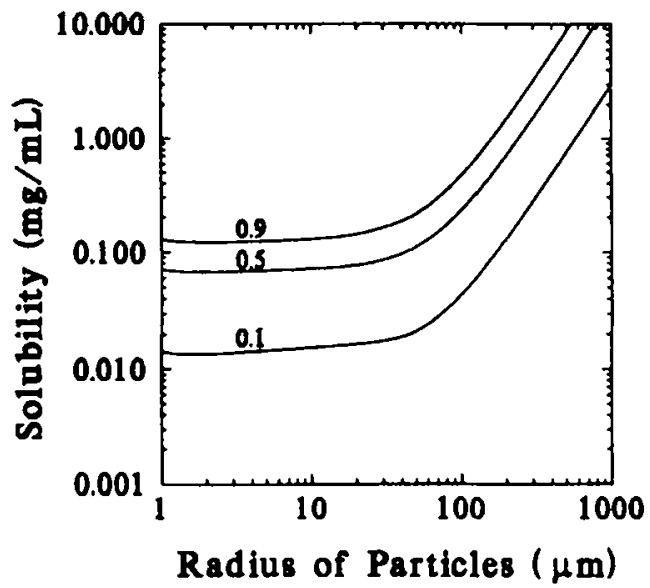

(B) $\mathrm{Mo} / \mathrm{Vo}=0.1 \mathrm{mg} / \mathrm{mL}$

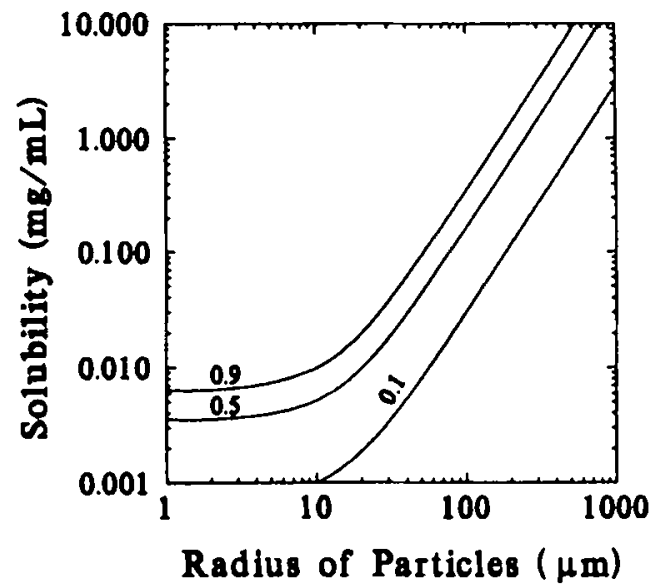

Fig. 7. Contours of fraction dose absorbed $(F)$ in the plot of solubility and radius of particles for $M_{0} / V_{0}=2 \mathrm{mg} / \mathrm{mL}(\mathrm{A})$ or 0.1 $\mathrm{mg} / \mathrm{mL}(\mathrm{B})$. Values of parameters used for calculations: $A n=7, i s=0$. 
(A) $\mathrm{Mo}=200 \mathrm{mg}$. ro $=9.25 \mu \mathrm{m}$

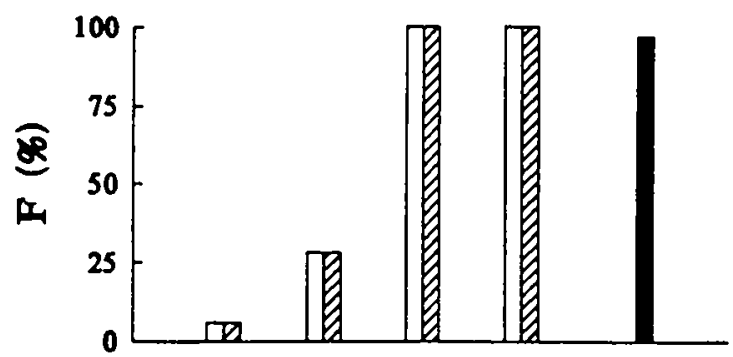

(B) $\mathrm{Mo}=200 \mathrm{mg}$. to $=305 \mu \mathrm{m}$

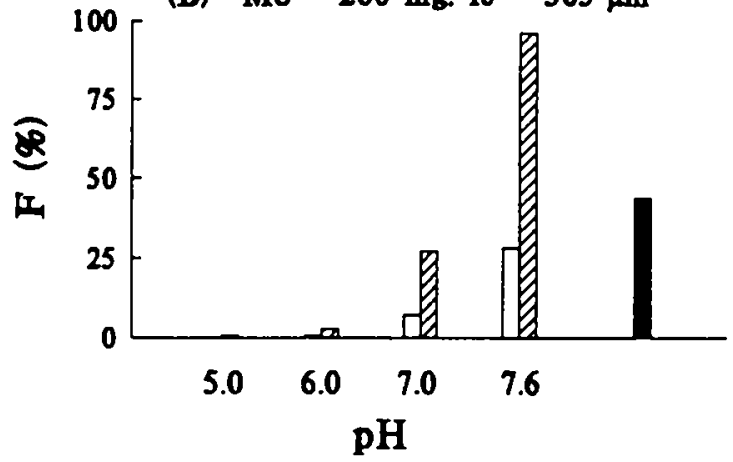

Fig. 8. Fraction dose absorbed $(F)$ of benoxaprofen at various $\mathrm{pH}$ values. Dose is $200 \mathrm{mg}$ and radii of particles are 9 . $25 \mu \mathrm{m}(\mathrm{A})$ or $305 \mu \mathrm{m}(\mathrm{B})$. The fractions dose absorbed are estimated using $l s=0$ or 1 and $A n=7$. The closed bars represent the reported values in the literature (Wolen et al., 1979).

- Wolen et al. (1979), : Estimated $F(\mid s=1), \square:$ Estimated $\mathrm{F}(\mathrm{I}=0)$

Table I. Estimated and reported fractions dose absorbed $(F)$ of benoxaprofen ${ }^{\mathrm{a}}$

\begin{tabular}{rrrrrrl}
\hline Do & \multicolumn{1}{l}{ Dn } & An & \multicolumn{2}{c}{ Estimated $F(\%)$} & Reported Reference \\
\cline { 3 - 6 } & & & \multicolumn{1}{l}{$l s=0$} & \multicolumn{1}{c}{$I s=1$} & $F(\%)$ & \\
\hline 2.7 & 0.07 & 7.0 & 6.7 & 42.3 & 60 & $\mathrm{~b}$ \\
2.7 & 6.72 & 7.0 & 100.0 & 100.0 & 100 & $\mathrm{~b}$ \\
7.7 & 52.40 & 7.0 & 100.0 & 100.0 & 98 & $\mathrm{c}$ \\
11.6 & 52.40 & 7.0 & 99.6 & 99.6 & 95 & $\mathrm{c}$ \\
4.8 & 88.18 & 7.0 & 100.0 & 100.0 & 96 & $\mathrm{~d}$ \\
4.8 & 0.08 & 7.0 & 7.2 & 27.0 & 41 & $\mathrm{~d}$ \\
19.3 & 0.08 & 7.0 & 6.7 & 11.3 & 22 & $\mathrm{~d}$ \\
\hline
\end{tabular}

density $=1000 \mathrm{mg} / \mathrm{ml}$, solubility $=0.207 \mathrm{mg} / \mathrm{ml}$ (at $\mathrm{pH}=7.0$ )

brom Ridolfo et al. (1979)

'from Nash et al. (1980)

'from Wolen et al. (1979).

$\mathrm{pH}$ where a drug has higher solubility. The calculated $F$ was somewhat underestimated compared to the reported $F$, suggesting a partial role of the intrinsic bile salts. In addition to the effect of bile salts, $\mathrm{pH}$ variation down the intestine may change the wall permeability of the compound. The physical model may be refined by introducting the effect of surfactants and ionization on $D n$ and $D o$.

In summary, the fraction dose absorbed of suspensions can be estimated from a dissolution model with parameters; $I s, A n, D o$, and $D n$. The dose, the radius of particles, and the solubility at the physiological $\mathrm{pH}$ are needed for estimation of $F$. About $90 \%$ of maximal $F$ can be achieved at $D n \approx 2$. Drugs with low Do and low $D n$ can be completely absorbed by reducing their particle sizes, while the absorption of drugs with high Do and low $D n$ is solubility (dose number) limited and requires a higher solubility, in addition to micronization, to enhance the fraction dose absorbed.

\section{ACKNOWLEDGEMENT}

This work supported in part by NIGMS Grant GM 37188 .

\section{REFERENCES CITED}

Abdou, H.M., Dissolution, Bioavailability, and Bioequivalence, Easton, Mack, 1989.

Atkinson, R.M., Bedford, C., Child, K.L. and Tomich, E.G., The effect of griseofulvin particle size on blood levels in man. Antibiotics and Chemotherapy, 12, 232-238 (1962).

Dressman, J.B., Kinetics of drug absorption from the gut, In J.G. Hardy, S. S. Davis and C.G. Wilson (eds.). Drug Delivery to the Gastrointestinal Tract. Ellix Honwood Limited, Chichester, 1989, pp. 195219.

Gibaldi, M., Biopharmaceutics and clinical pharmacokinetics. 3rd ed., Lea \& Febiger, Philadephia, 1984, pp. 44-63.

Johnson, B.F., O'Grady, J. and Bye, G., The influence of digoxin particle size on absorption of digoxin and the effect of propantheline and metoclopramide. Br. J. Clin. Pharmac., 5, 465-467 (1978).

Jounela, A.J., Pentikäinen, P.J. and Sothmann, A., Effect of particle size on the bioavailability of digoxin. Europ. J. Clin. Pharmacol., 8, 365-370 (1975).

Khalafalla, N., Elgholmy, Z.A. and Khalil, S.A., Bioavailability of different brands of griseofulvin tablets and its correlation to dissolution data. Pharmazie, 35, 482-484 (1980).

Leeson, L.J. and Carstensen J.T., Dissolution Technology. The Industrial Pharmaceutical Technology Section of the Academy of Pharmaceutical Science, Washington, D.C., 1974.

Miyazaki, S., Yamahira, T., Inoue, H. and Nadai, T., Interaction of drugs with bile components. II. Effect of bile on the absorption of indomethacin and phenlbutazine in rats. Chem. Pharm. Bull., (Tokyo) 28, 323-326 (1980).

Nash, J.F., Carmichael, R.H., Ridolfo, A.S. and Spradlin, C.T., Pharmacokinetic studies of benoxaprofen after therapeutic doses with a review of related 
pharmacokinetic and metabolic studies, J. Rheumat. Suppl., 6, 12-19 (1980).

Oh, D.-M., Curl, R.L. and Amidon, G.L., Estimating the fraction dose absorbed from suspensions of poorly soluble compounds in humans: a mathematical model. Pharm. Res., 10, 264-270 (1993).

Oh, D.-M. and Amidon, G.L., Prediction of drug-drug interaction during oral absorption of carrier-mediated compounds in humans. Arch. Pharm. Res., 17, 364-370 (1994).

Poelma, F.G.J., Intestinal Absortion of Drugs: The Influence of Taurocholate on the Absorption of Drugs in the Small Intestine of the Rat, Ph.D. Thesis, The University of Utrecht, The Netherlands, 1989.

Ridolfo, A.S., Thompkins, L., Bechtol, L.D. and Carmichael, R.H., Benoxaprofen, a new anti-inflammatory agent: particles-size effect of dis- solution rate and oral absorption in humans. I. Pharm. Sci., 68, 850-852 (1979).

Shaw, T.R.D. and Carless, J.E., The effect of particle size on the absorption of digoxin. Eur. /. Clin. Pharmacol., 7, 269-273 (1974).

Sinko, P.J., Lessman, G.D. and Amidon, G.L., Predicting fraction dose absorbed in humans using a macroscopic mass balance approach. Pharm. Res., 8, 979-988 (1991).

Terhaatg, B., Petit, G.L., Pachaly, C. and Feller, K., The in vitro liberation and the bioavailability of different brands of griseofulvin in plasma and urine in man. Int. J. Clin. Pharmacol. Ther. Toxicol., 23, 475-479 (1985).

Wolen, R.L., Carmichael, R.H., Ridolfo, A.S., Thompkins, L. and Ziege, E.A., The effect of crystal size on the bioavailability of benoxaprofen: studies utilizing deuterium labreled drug. Biomed. Mass Spectrometry, 6, 173-178 (1979). 